\title{
Effects of inflammation and fibrosis on pulmonary function in diffuse lung fibrosis
}

\author{
Thierry Chinet, Francis Jaubert, Daniel Dusser, Claire Danel, Jacques Chrétien, \\ Gérard J Huchon
}

\begin{abstract}
To investigate the relation between lung function and inflammation and fibrosis in patients with diffuse lung fibrosis, a study was made of untreated patients without appreciable airway obstruction (14 patients with cryptogenic fibrosing alveolitis and seven with pneumoconiosis). Quantitative assessment of inflammatory infiltration and fibrosis was carried out on open lung biopsy specimens and compared with lung volumes, carbon monoxide transfer factor (TLCO), TLCO corrected for alveolar volume (TLCo/VA), and arterial blood gases at rest and during exercise. The degree of fibrosis and the degree of cellular infiltration were positively correlated. Lung volumes and TLCo were correlated with the grades of fibrosis and cellular infiltration of alveoli; arterial blood gases during exercise tended to correlate with both fibrosis and infiltration $(p<0.06)$. In contrast, morphological data were not correlated with gas exchange at rest or with TLCo/VA. It is concluded that, in untreated patients with diffuse lung fibrosis, lung volumes, TLCO, and arterial blood gases during exercise reflect the lung lesions, and that the pulmonary function tests used cannot discriminate between fibrosis and infiltration of the lung by inflammatory cells.
\end{abstract}

Diffuse lung fibrosis begins with an infiltration of alveoli by inflammatory cells, and progresses to fibrosis. ${ }^{1-3}$ Cellular infiltration may reverse spontaneously or as a result of treatment, whereas no studies have shown reversal of lung fibrosis. ${ }^{24}$ It is important for the management of patients with diffuse lung fibrosis to assess the relative extent of inflammation and fibrosis because inflammation is potentially reversible but fibrosis appears not to be. ${ }^{5}$ Their extent may be determined by open lung biopsy, ${ }^{47}$ but this can usually be carried out only once. Pulmonary function tests allow serial evaluations of the consequences of diffuse lung fibrosis on lung function. Few studies, however, have evaluated structure-function correlates in diffuse lung fibrosis, and their findings do not agree. ${ }^{8-11}$ The effects of cellular infiltration and fibrosis on lung function are not known, and there are no data to determine whether pulmonary function tests can predict the relative contri- butions of cellular infiltration and fibrosis to functional impairment of the lung.

We have therefore studied patients with lung fibrosis, without airflow limitation, who were not receiving corticosteroid or immunosuppressive treatment. We attempted to determine whether pulmonary function tests might predict the relative contributions of fibrosis and cellular infiltration to lung damage.

\section{Methods}

PATIENTS

We studied 21 patients with a diagnosis of diffuse lung fibrosis confirmed by open biopsy. The age of the patients (14 male, seven female) ranged from 24 to 75 (mean 50.8 (SD 13.2)) years. The lung disease was classified according to clinical, biological, radiographic, and histological criteria ${ }^{712}$ as cryptogenic fibrosing alveolitis in 14 patients (including one with multiple sclerosis and one with mixed connective tissue disease) and pneumoconiosis in seven (including two patients with silicosis). There were six smokers, 10 non-smokers, and five ex-smokers (table 1). To be considered an ex-smoker a patient must have given up smoking at least one year before. No patient was receiving anti-inflammatory or immunosuppressive treatment at the time of pulmonary function tests or lung biopsy, and none had airway obstruction, defined as a ratio of forced expiratory volume in one second $\left(F E V_{1}\right)$ to forced vital capacity (FVC) below $86 \%$ of the predicted value.

\section{PULMONARY FUNCTION TESTING}

Pulmonary function tests were performed in all patients not more than one month before open lung biopsy. FEV 1 and FVC were measured by spirometer with the patient in a sitting position. Total lung capacity (TLC) was derived from functional residual capacity (FRC) determined by multiple breath helium dilution. Results were expressed as a percentage of the predicted values from the European Coal and Steel Community survey. ${ }^{13}$ Transfer factor for carbon monoxide (TLCO) was measured by the breath holding technique and was expressed as a percentage of the predicted values based on age and height. The simultaneous measurement of alveolar volume (VA) using the helium dilution technique allowed calculation of the transfer coefficient ( $T_{L}$ Co/VA), which was expressed as a percentage of the predicted 
Table 1 Individual clinical and pathological data in patients with fibrosing lung disease

\begin{tabular}{rllllll}
\hline $\begin{array}{l}\text { Patient } \\
\text { No }\end{array}$ & $\begin{array}{c}\text { Age } \\
(y)\end{array}$ & Sex & Aetiology & Smoking & $\begin{array}{l}\text { Grade of } \\
\text { fibrosis }\end{array}$ & $\begin{array}{l}\text { Grade of } \\
\text { cellular } \\
\text { infiltration }\end{array}$ \\
\hline 1 & 40 & M & CFA & Smoker & 1 & 1 \\
2 & 64 & F & CFA & Non-smoker & 1 & 1 \\
3 & 37 & M & PNM & Non-smoker & 1 & 1 \\
4 & 60 & M & PNM & Smoker & 1 & 1 \\
5 & 44 & M & PNM & Non-smoker & 2 & 2 \\
6 & 50 & M & PNM & Non-smoker & 1 & 1 \\
7 & 41 & M & PNM & Non-smoker & 2 & 2 \\
8 & 44 & M & PNM & Ex-smoker & 2 & 2 \\
9 & 40 & M & PNM & Ex-smoker & 1 & 1 \\
10 & 59 & F & CFA & Non-smoker & 1 & 1 \\
11 & 54 & F & CFA & Ex-smoker & 3 & 2 \\
12 & 75 & M & CFA & Ex-smoker & 2 & 2 \\
13 & 71 & M & CFA & Ex-smoker & 3 & 2 \\
14 & 37 & M & CFA & Smoker & 1 & 3 \\
15 & 57 & F & CFA & Non-smoker & 3 & 1 \\
16 & 56 & F & CFA & Smoker & 3 & 3 \\
17 & 60 & M & CFA & Smoker & 2 & 2 \\
18 & 55 & F & CFA & Non-smoker & 2 & 1 \\
19 & 34 & F & CFA & Non-smoker & 2 & 2 \\
20 & 65 & M & CFA & Non-smoker & 3 & 2 \\
21 & 24 & M & CFA & Smoker & 1 & 1 \\
\hline
\end{tabular}

CFA—cryptogenic fibrosing alveolitis; PNM-pneumoconiosis.

Table 2 Mean (SD) and range of pulmonary function values in patients with diffuse lung fibrosis

\begin{tabular}{|c|c|c|c|}
\hline & Mean (SD) & Range & $n$ \\
\hline TLC $\left({ }^{\circ}{ }_{0}\right.$ pred $)$ & $75 \cdot 7(22.9)$ & $\begin{array}{ll}40 & -127\end{array}$ & 21 \\
\hline FVC $\left({ }^{\circ}{ }_{0}^{\circ}\right.$ pred $)$ & $66.4(23.9)$ & $42-135$ & 21 \\
\hline $\mathrm{FEV}_{1}\left({ }^{\circ}{ }_{0}\right.$ pred $)$ & $66 \cdot 2(18 \cdot 2)$ & $41-108$ & 21 \\
\hline TLCo ( ${ }_{0}{ }_{0}$ pred) & $53.5(26.8)$ & $21-97$ & 13 \\
\hline TLco/VA (o, pred) & $66.8(20 \cdot 1)$ & $31-91$ & 13 \\
\hline Resting $\mathrm{PaO}_{2}(\mathrm{~mm} \mathrm{Hg})$ & $78 \cdot 4(12 \cdot 0)$ & $52-99$ & 21 \\
\hline Exercise $\mathrm{PaO}_{2}(\mathrm{~mm} \mathrm{Hg})$ & $66 \cdot 4(16 \cdot 1)$ & $42-95$ & 17 \\
\hline Resting $\mathrm{A}-\mathrm{aDo}_{2}(\mathrm{~mm} \mathrm{Hg})$ & $20.4(13 \cdot 3)$ & $-3 \cdot 3-43 \cdot 8$ & 21 \\
\hline Exercise $\mathrm{A}-\mathrm{aDO}_{2}(\mathrm{~mm} \mathrm{Hg})$ & $32.8(15.0)$ & $-3 \cdot 0-53 \cdot 8$ & 17 \\
\hline
\end{tabular}

TLC - total lung capacity; FVC_-forced vital capacity; $\mathrm{FEV}_{1}$-forced expiratory volume in one second; TLCo-transfer factor for carbon monoxide; VA-alveolar volume; $\mathrm{A}-\mathrm{aDo}_{2}-$ alveolararterial oxygen difference.

$1 \mathrm{~mm} \mathrm{Hg} \approx 0.133 \mathrm{kPa}$

Table 3 Correlations of transfer factor and gas exchange data with the grades of fibrosis and cellular infiltration in patients with diffuse lung fibrosis

\begin{tabular}{|c|c|c|c|c|}
\hline \multirow{2}{*}{$\begin{array}{l}\text { Pulmonary } \\
\text { function test }\end{array}$} & \multicolumn{2}{|l|}{ Fibrosis } & \multicolumn{2}{|c|}{ Cellular infiltration } \\
\hline & $r_{s}$ & $p$ & $r_{s}$ & $p$ \\
\hline $\begin{array}{l}\text { TLCo } \\
\text { TLCo/VA } \\
\text { Resting } \mathrm{PaO}_{2} \\
\text { Exercise } \mathrm{PaO}_{2} \\
\text { Resting } \mathrm{A}-\mathrm{aDO}_{2} \\
\text { Exercise } \mathrm{A}-\mathrm{aDO}_{2}\end{array}$ & $\begin{array}{l}-0.811 \\
-0.466 \\
-0.135 \\
-0.486 \\
+0.096 \\
+0.525\end{array}$ & $\begin{array}{l}<0.001 \\
\text { NS } \\
\text { NS } \\
0.052 \\
\text { NS } \\
<0.05\end{array}$ & $\begin{array}{l}-0.622 \\
-0.434 \\
+0.037 \\
-0.472 \\
-0.125 \\
+0.408\end{array}$ & $\begin{array}{l}<0.01 \\
\text { NS } \\
\text { NS } \\
0.059 \\
\text { NS } \\
\text { NS }\end{array}$ \\
\hline
\end{tabular}

$r_{S}$-Spearman's rank coefficient. Other abbreviations as in table 2. value based on age and alveolar volume. Blood gases were determined in samples obtained from a radial artery, at rest and during exercise on a cycle ergometer (50-100 watts for 35 minutes). The work load was progressively increased until the patient complained of considerable breathlessness. Arterial oxygen $\left(\mathrm{PaO}_{2}\right)$ and carbon dioxide tensions $\left(\mathrm{PaCO}_{2}\right)$ were measured, and the alveolar-arterial oxygen tension difference $\left(\mathrm{A}-\mathrm{aDO}_{2}\right)$ was calculated by means of the alveolar equation during steady state conditions, on the assumption of a respiratory gas exchange ratio of $0 \cdot 8$.

\section{PATHOLOGICAL EVALUATION}

Pathological examinations were carried out without knowledge of the functional data. Biopsy samples were taken from a representative diseased area as judged by the chest radiograph and the macroscopic appearance of the lung at surgery. Biopsy specimens were inflated, fixed in $10 \%$ neutral formalin, and embedded in paraffin. For each case $5 \mu \mathrm{m}$ sections obtained from three or four blocks of $2 \times 1 \times 0.5 \mathrm{~cm}$ were stained with haemateineosin-safran and studied at a magnification of 200. The degrees of fibrosis and infiltration of terminal respiratory units in each tissue section were evaluated independently; grade 0 was defined as fibrosis or inflammation of less than $10 \%$ of the surface of the lung section, grade 1 as $10-30 \%$, grade 2 as $30-60 \%$ and grade 3 as more than $60 \%$. The predominant cell types within the inflammatory infiltration were identified (macrophage, lymphocyte, or neutrophil). Bronchiolar and vascular disease was recorded as absent or present.

\section{STATISTICAL ANALYSIS}

Relationships between histological and functional data were analysed by Spearman's rank correlation coefficient and comparison between groups and relation to predominant cell type by the Mann-Whitney U test. Values of p below 0.05 were considered significant. ${ }^{14}$

\section{Results}

Individual clinical and pathological data are presented in table 1 and mean pulmonary function data in table 2 . The grade of fibrosis correlated with the grade of cellular infiltration $\left(r_{s}=+0.573, p<0.02\right)$.

There was no difference between the patients with pneumoconiosis and those with

Table 4 Correlations between lung volumes and the grades of fibrosis and cellular infiltration in patients with cryptogenic fibrosing alveolitis (CFA) and patients with pneumoconiosis (PNM)

\begin{tabular}{|c|c|c|c|c|c|}
\hline \multirow{2}{*}{$\begin{array}{l}\text { Pulmonary } \\
\text { function test }\end{array}$} & \multirow[b]{2}{*}{ Disease } & \multicolumn{2}{|l|}{ Fibrosis } & \multicolumn{2}{|c|}{ Cellular infiltration } \\
\hline & & $r_{s}$ & $p$ & $r_{s}$ & $p$ \\
\hline TLC & $\begin{array}{l}\text { CFA } \\
\text { PNM }\end{array}$ & $\begin{array}{l}-0.735 \\
-0.866\end{array}$ & $\begin{array}{l}<0.01 \\
<0.05\end{array}$ & $\begin{array}{l}-0.705 \\
-0.866\end{array}$ & $\begin{array}{l}<0.02 \\
<0.05\end{array}$ \\
\hline FVC & $\begin{array}{l}\text { CFA } \\
\text { PNM }\end{array}$ & $\begin{array}{l}-0.598 \\
-0.866\end{array}$ & $\begin{array}{l}<0.05 \\
<0.05\end{array}$ & $\begin{array}{l}-0.201 \\
-0.866\end{array}$ & $\begin{array}{l}\text { NS } \\
<0.05\end{array}$ \\
\hline $\mathrm{FEV}_{1}$ & $\begin{array}{l}\text { CFA } \\
\text { PNM }\end{array}$ & $\begin{array}{l}-0.231 \\
-0.577\end{array}$ & $\begin{array}{l}\text { NS } \\
\text { NS }\end{array}$ & $\begin{array}{l}-0.364 \\
-0.577\end{array}$ & $\begin{array}{l}\text { NS } \\
\text { NS }\end{array}$ \\
\hline
\end{tabular}

TLC — total lung capacity; FVC—-forced vital capacity; $\mathrm{FEV}_{1}$ - forced expiratory volume in one second; $r_{S}-\mathrm{Spearman}$ 's rank coefficient. 
cryptogenic fibrosing alveolitis in terms of age, histological gradings, or lung function, except that FVC and $\mathrm{FEV}_{1}$ were reduced to a greater extent in the patients with cryptogenic fibrosing alveolitis than in those with pneumoconiosis ( $p<0.05$ for both). Except for lung volumes therefore we considered the patients as a single group for the purpose of analysis.

Correlations between the grades of cellular infiltration and of fibrosis and the transfer factor and gas exchange data are shown in table 3. Pathological grade was correlated with TLCo but not with TLCO/VA. This might be related to the volume dependence of TLCO because, as expected, total lung capacity was correlated with TLCO $\left(\mathrm{r}_{\mathrm{s}}=0.707, \mathrm{p}<0.01\right)$ but not with TLCo/VA $\left(\mathrm{r}_{\mathrm{s}}=0.419, \mathrm{NS}\right)$. The pathological changes showed a closer correlation with exercise $\mathrm{Po}_{2}$ and $\mathrm{A}-\mathrm{aDO}_{2}$ than with resting oxygen values.

The pathological data were correlated with total lung capacity and FVC in both groups of patients except that FVC was not correlated with cellular infiltration in the patients with fibrosing alveolitis (table 4).

There was no relation between lung function and the predominant cell type observed in the cellular infiltration of the lung. Inflammatory changes were seen to affect bronchioles (12 patients) and pulmonary vasculature (13 patients), but these changes did not show an association with lung function.

\section{Discussion}

In our study of patients with diffuse lung fibrosis, firstly, cellular infiltration and fibrosis were positively correlated; secondly, lung volumes and TLCO were correlated with both cellular infiltration and fibrosis; and, thirdly, arterial blood gas tensions during exercise tended to correlate with both infiltration and fibrosis whereas TLCO/VA and arterial blood gases at rest did not.

Our finding that both fibrosis and cellular infiltration are related to lung volumes, TLCo, and probably arterial blood gas tensions during exercise contrasts with the results of previous studies. In 23 patients with diffuse lung fibrosis Fulmer et $a l^{8}$ found no relation between either the severity of fibrosis or the degree of cellular infiltration and lung volumes, diffusing capacity, or $\mathrm{PaO}_{2}$ at rest or during maximal exercise. Green et al studied 25 patients with interstitial pulmonary disease and found that the intensity of fibrosis-but not that of cellular infiltration-was related to lung volumes and to gas exchange at rest and during exercise; no relationship was found between histological changes and diffusing capacity. ${ }^{9}$ In patients who had an open lung biopsy for various types of chronic diffuse infiltrative lung disease Gaensler and Carrington found a correlation between an index of pathological severity and lung volumes as well as diffusing capacity and $\mathrm{A}-\mathrm{aDo}_{2}$ during exercise. ${ }^{11}$ In view of the previous studies, Keogh and Crystal proposed that in idiopathic pulmonary fibrosis lung volumes roughly parallel the severity of fibrosis, but bear no relation to the extent of alveolitis. ${ }^{3}$ They suggested that measurement of gas exchange during exercise is the most sensitive test of functional impairment, whereas TLCO and arterial blood gas tensions at rest bear little or no relation to the extent of the disease. $^{3}$

The selection of patients may explain the discrepancy between our findings and those of others. In previous studies a large proportion of patients had been given corticosteroids by the time of biopsy, ${ }^{8}$ pulmonary function tests were performed after open lung biopsy, ${ }^{10}$ or patients had unrelated associated pulmonary diseases such as chronic airflow limitation. ${ }^{810}$ We excluded patients with central airway obstructive disease and patients receiving corticosteroid or immunosuppressive treatment at the time of assessment because central airway obstruction is not a feature of diffuse lung fibrosis (in contrast to small airway obstruction ${ }^{15}$ ) and corticosteroid and immunosuppressive treatments are likely to reduce inflammation but have little or no effect on fibrosis. If patients undergoing such treatment had been included, the number of patients with severe functional impairment and increased cellular infiltration may have been artificially reduced and the relation between cellular infiltration and the results of pulmonary function tests difficult to establish.

We found a positive correlation between the intensity of cellular infiltration and that of fibrosis. Fulmer et al did not specifically address this point but, using their data, we computed the Spearman's correlation coefficient between the degrees of cellular infiltration and of fibrosis, and found that they did correlate $\left(r_{s}=0.439, p<0.05\right)$. Haslam et al found that in most of their patients with idiopathic fibrosing pneumonitis cellular infiltration and fibrosis were present simultaneously and were severe. ${ }^{16}$ Our finding that the intensity of fibrosis correlates with that of cellular infiltration may seem surprising as, according to current concepts of the pathogenesis of diffuse lung fibrosis, the fibrosis progresses during the course of the disease whereas inflammation predominates in the early stages. In practice, diagnosis and assessment usually occur when patients are somewhere between the early stage of the disease (when cellular infiltration is predominant) and the end stage, when fibrosis is advanced ("honeycomb lung") and functional impairment does not allow open lung biopsy. Our patients (and patients in other studies) had mid stage disease and had both inflammation and fibrosis. As fibrosis is induced by inflammation mediated damage of alveolar structures, ${ }^{2}$ intense cellular infiltration of the alveolar structures results in more extensive alveolar injury and more intense fibrotic lesions. ${ }^{17} 18$

Clinical data, as well as structure-function studies in animal models, suggest that inflammation impairs lung volumes and gas exchange. ${ }^{18-22}$ In 120 patients with idiopathic fibrosis, Rudd et al found that patients improving with corticosteroids or immunosuppressive drugs had more severe impairment of FVC; as 
fibrotic lesions are not reversible, cellular infiltration of lung parenchyma was likely to be responsible for the initial reduction in lung volumes. ${ }^{19}$ Animal studies have shown that during the initial inflammatory stage the extent of histological change is reflected in functional studies by a decrease in lung volumes and in carbon monoxide transfer factor and by impairment of arterial blood gases. ${ }^{20-22}$

In conclusion, our study shows that lung volumes, TLCO, and probably arterial blood gases during exercise are related to cellular infiltration and to fibrosis. Pulmonary function tests do not appear to discriminate between the relative contributions of cellular infiltration and fibrosis to functional impairment.

This work was supported by a grant from the Association pour l'Etude de la Respiration et de l'Environnement.

1 Crystal RG, Bitterman PB, Rennard SI, Hance AJ, Keogh BA. Interstitial lung diseases of unknown cause. Disorders characterized by chronic cellular infiltration of the lower respiratory tract. $N$ Engl J Med 1984;310:154-66.

2 Hunninghake GW, Garett KC, Richerson HB, et al. Pathogenesis of the granulomatous lung diseases. Am Rev Respir Dis 1984;130:476-96.

3 Keogh BA, Crystal RG. Clinical significance of pulmonary function tests. Pulmonary function testing in interstitial pulmonary disease. What does it tell us? Chest 1980;6: $856-65$.

4 Winterbauer RH, Hammar SP, Hallman KO, et al. Diffuse interstitial pneumonitis. Clinicopathologic correlations in 20 patients treated with prednisone/azathioprine. $\mathrm{Am} \mathrm{J}$ Med 1978;65:661-72.

5 Raghu G. Idiopathic pulmonary fibrosis. A rational clinical approach. Chest 1987;92:148-54.

6 Venn GE, Kay PH, Midwood CJ, Goldstraw P. Open lung biopsy in patients with diffuse pulmonary shadowing. Thorax 1985;40:931-5

7 Crystal RG, Fulmer JD, Roberts WC, Moss ML, Line BR, Reynolds HY. Idiopathic pulmonary fibrosis. Clinical, histologic, radiographic, physiologic, scintigraphic, cytologic, and biochemical aspects. Ann Intern Med cytologic, and

8 Fulmer JD, Roberts WC, Von Gal R, Crystal RG. Mor- phologic-physiologic correlates of the severity of fibrosis and degree of cellular infiltration in idiopathic pulmonary fibrosis. J Clin Invest 1979;63:665-76.

9 Green GM, Graham GB, Hanson JS, et al. Correlated studies of interstitial pulmonary disease. Chest 1976;69(suppl 2):263

10 Gaensler EA, Carrington CB, Coutu RE, FitzGerald MX. Radiographic-physiologic-pathologic correlations in interstitial pneumonias. Prog Respir Res 1975;8:223-41.

11 Gaensler EA, Carrington CB. Open biopsy for chronic diffuse infiltrative lung disease: clinical, roentgenographic and physiologic correlations in 502 patients. Ann Thorac Surg 1980;30:411-26.

12 Crystal RG, Gadek JE, Ferrans VJ, Fulmer JD, Line BR, Hunninghake $\mathrm{GW}$. Interstitial lung disease: current concepts of pathogenesis, staging and therapy. $A m \mathrm{~J} \mathrm{Med}$ 1981;70:542-68.

13 European Coal and Steel Community. Standardised lung function testing. Bull Eur Physiopathol Respir 1983;19 (suppl 5):1-93.

14 Remington DR, Schork MA. Statistics with applications to the biological and health sciences. Englewood Cliffs, New Jersey: Prentice-Hall, 1985;i:310-26.

15 Fulmer JD, Roberts WC, Von Gal ER, Crystal RG. Small airways in idiopathic pulmonary fibrosis. Comparison of morphologic and physiologic observations. J Clin Invest 1977;60:595-610.

16 Haslam PL, Turton CWG, Heard B, et al. Bronchoalveolar lavage in pulmonary fibrosis: comparison of cells obtained with lung biopsy and clinical features. Thorax 1980;35 with 9 -18.

17 Witschi HP, Hascher WM, Klein-Szanto AJP, Hakkinen PJ. Potentiation of diffuse lung damage by oxygen: determining variables. Am Rev Respir Dis 1981;123: 98-103.

18 Katzenstein ALA, Askin FB. Diffuse alveolar damage. In: Bennington JL, ed. Surgical pathology of non-neoplastic Bennisease. Philadelphia: Saunders Company, 1982:9-42.

19 Rudd RM, Haslam PL, Turner-Warwick M. Cryptogenic fibrosing alveolitis. Relationship of pulmonary physiology and bronchoalveolar lavage to response treatment and prognosis. Am Rev Respir Dis 1981;124:1-8.

20 McCullough B, Collins JF, Johanson WG Jr, Grover FL. Bleomycin-induced diffuse interstitial pulmonary fibrosis in baboons. $J$ Clin Invest 1978;61:79-88.

21 Snider GL, Hayes JA, Korthy AL. Chronic interstitial pulmonary fibrosis produced in hamsters by endotracheal bleomycin. Pathology and stereology. Am Rev Respir Dis 1978;117:1099-108.

22 Snider GL, Celli BR, Goldstein RH, O'Brien JJ, Lucey EC. Chronic interstitial pulmonary fibrosis produced in hamsters by endotracheal bleomycin. Lung volumes, volumepressure relations, carbon monoxide uptake, and arterial blood gas studies. Am Rev Respir Dis 1978;117:289-97. 